\title{
Risk of ruling out severe acute respiratory syndrome by ruling in another diagnosis: Variable incidence of atypical bacteria coinfection based on diagnostic assays
}

\author{
George Zahariadis $\mathrm{MD}^{1}$, Ted A Gooley $\mathrm{PhD}^{2}$, Phyllis Ryall RN³ , Christine Hutchinson BScN3 , \\ Mary I Latchford BSc ${ }^{3}$, Margaret A Fearon $\mathrm{MD}^{4}$, Frances B Jamieson $\mathrm{MD}^{4}$, Susan Richardson $\mathrm{MD}^{5,6}$, \\ Theodore Kuschak $\mathrm{PhD}^{7}$, Barbara Mederski MD ${ }^{3}$
}

G Zahariadis, TA Gooley, P Ryall, et al. Risk of ruling out severe acute respiratory syndrome by ruling in another diagnosis: Variable incidence of atypical bacteria coinfection based on diagnostic assays. Can Respir J 2006;13(1):17-22.

BACKGROUND: Severe acute respiratory syndrome (SARS) caused the first epidemic of the 21st century and continues to threaten the global community.

OBJECTIVE: To assess the incidence of coinfection in patients confirmed to have SARS-associated coronavirus (SARS-CoV) infection, and thus, to determine the risk of ruling out SARS by ruling in another diagnosis.

METHODS: The present report is a retrospective study evaluating the incidence and impact of laboratory-confirmed SARS-CoV and other pulmonary pathogens in 117 patients. These patients were evaluated in a Toronto, Ontario, community hospital identified as the epicentre for the second SARS outbreak.

RESULTS: Coinfection with other pulmonary pathogens occured in patients with SARS. Seventy-three per cent of the patient population evaluated had laboratory-confirmed SARS-CoV infection. Serology showing acute or recent Chlamydophila pneumoniae or Mycoplasma pneumoniae infection revealed an incidence of $30 \%$ and $9 \%$, respectively, in those with SARS. These rates are similar to previously published studies on coinfection in pneumonia. All nucleic acid diagnostic assays were negative for $\mathrm{C}$ pneumoniae and $\mathrm{M}$ pneumoniae in respiratory samples from patients with SARS having serological evidence for these atypical pathogens.

CONCLUSIONS: Diagnostic assays for well-recognized pulmonary pathogens have limitations, and ruling out SARS-CoV by ruling in another pulmonary pathogen carries significant risk. Despite positive serology for atypical pathogens, in a setting where clinical suspicion for SARS is high, specific tests for SARS should be performed to confirm or exclude a diagnosis.

Key Words: Coinfection; Coronavirus; Epidemic; Pneumonia; SARS
Le risque d'écarter un diagnostic de syndrome respiratoire aigu sévère en faveur d'un autre diagnostic : Incidence variable des co-infections bactériennes atypiques selon les tests diagnostiques

HISTORIQUE : Le syndrome respiratoire aigu sévère (SRAS) a causé la première épidémie du $21^{\mathrm{e}}$ siècle et continue de représenter une menace globale pour l'être humain.

OBJECTIF : Mesurer l'incidence des co-infections chez les patients avérés infectés par le coronavirus associé au SRAS (SRAS-coV) et déterminer ainsi s'il y a un risque à écarter un diagnostic de SRAS en faveur d'un autre diagnostic.

MÉTHODES : Le présent rapport décrit une étude rétrospective qui visait à évaluer l'incidence et l'impact du SRAS-coV et d'autres pathogènes pulmonaires confirmés en laboratoire chez 117 patients. Ces patients ont été examinés dans un hôpital communautaire de Toronto, en Ontario, identifié comme l'épicentre de la seconde éclosion de SRAS.

RÉSULTATS : La co-infection par d'autres pathogènes pulmonaires a été notée chez des patients victimes du SRAS. Soixante-treize pour cent de la population de patient évalués présentaient une infection à SRAS-coV, analyses de laboratoires à l'appui. Des épreuves sérologiques ont révélé la présence d'infections aiguës ou récentes à Chlamydophila pneumoniæ ou à Mycoplasma pneumonix, selon une incidence respective de $30 \%$ et de $9 \%$ chez les sujets atteints de SRAS. Ces taux font écho aux résultats enregistrés lors d'études publiées antérieurement sur la co-infection dans la pneumonie. Tous les tests diagnostiques reposant sur l'amplification génique de l'acide nucléique se sont révélés négatifs à l'égard de $\mathrm{C}$ pneumoniæ et de $\mathrm{M}$ pneumoniæ dans les spécimens respiratoires provenant de patients atteints de SRAS, alors que les épreuves sérologiques indiquaient la présence de ces pathogènes atypiques. CONCLUSIONS : Les tests diagnostiques de dépistage des pathogènes respiratoires bien connus ont des limites et le fait d'écarter un diagnostic de SRAS-coV en faveur d'un autre pathogène pulmonaire comporte un risque important. Malgré les tests sérologiques positifs, dans un contexte clinique où on soupçonne fort l'implication du SRAS, des tests spécifiques de dépistage du SRAS doivent être effectués pour confirmer ou infirmer le diagnostic.
Severe acute respiratory syndrome (SARS) was initially Sreported in southern China in November $2002(1,2)$. It received international attention after persons exposed to an ill patient in a Hong Kong hotel travelled internationally and subsequently infected other persons in early 2003 (3). One such person returned to Toronto, Ontario, and infected several others, triggering the first outbreak of SARS in Toronto (4). The causative agent has since been identified as a novel coronavirus (SARS-associated coronavirus [SARS-CoV]) (5-9). SARS is a syndrome typically characterized by fever and respiratory symptoms with associated chest $\mathrm{x}$-ray abnormalities, similar to infections caused by several other pulmonary pathogens $(1,2,4)$. Initial case definitions by the World Health Organization and the United States Centers for Disease Control and Prevention

${ }^{1}$ University of Alberta, Edmonton, Alberta; ${ }^{2}$ Fred Hutchinson Cancer Research Center, Seattle, Washington, USA; ${ }^{3}$ North York General

Hospital; ${ }^{4}$ Ministry of Health and Long-Term Care - Laboratories Branch; ${ }^{5}$ The Hospital for Sick Children; ${ }^{6}$ University of Toronto, Toronto,

Ontario; ${ }^{7}$ Health Canada National Microbiology Laboratory, Winnipeg, Manitoba

Correspondence: Dr George Zahariadis, University of Alberta and Provincial Laboratory for Public Health (Alberta), Walter MacKenzie Centre,

Room 2B1.04, 8440 - 112 Street, Edmonton, Alberta T6G 2J2. Telephone 780-407-8975, fax 780-407-8961, e-mail georgez@ualberta.ca 
(CDC) required the presence of fever, respiratory symptoms, an epidemiological link and radiographic features $(10,11)$. This original CDC case definition added that the respiratory illness was without known etiology (11). Currently, a rapid point-ofcare test is not available and SARS diagnostic tests continue to evolve. Case definitions have since been updated to include SARS-specific laboratory assays $(10,11)$.

Throughout the first SARS epidemic in Toronto, when private and negative-pressure rooms were few, identification of other pulmonary microbial pathogens that helped to explain symptoms was considered as grounds to exclude SARS. In fact, patients were excluded from previously published SARS studies if another microbial pathogen was identified to explain the clinical presentation (12). Toronto experienced a second SARS epidemic, with North York General Hospital (NYGH), a Toronto community hospital, as the epicentre. Recognition of this outbreak was delayed, in great part because of a lack of an epidemiological link in ill patients and also because other more common pathogens or respiratory conditions were considered more likely for causing the patients' symptoms. It is now known that certain patients were coinfected with SARS-CoV and other pulmonary pathogens.

Briefly, the literature on community-acquired pneumonia (CAP) documents a dual pathogen infection incidence between $3 \%$ and $40 \%$, predominantly with pathogens causing atypical pneumonia (13-15). These pneumonia studies diagnosed Chlamydophila pneumoniae and Mycoplasma pneumoniae by serology. Noteworthy, a SARS study from Hong Kong that used serological assays failed to detect atypical respiratory pathogen coinfection (16). Nevertheless, before the SARS-CoV was identified, initial reports from China documented Chlamydophila-like particles in addition to coronavirus by electron microscopy of respiratory specimens obtained from autopsied SARS patients (17). Moreover, early efforts to identify the SARS-causing pathogen identified a novel coronavirus, as well as metapneumovirus (18). These findings raised the question of whether coinfection of Chlamydophila or other pulmonary pathogens in SARS-CoV-infected patients played a role in disease severity and mortality.

In patients presenting with fever and respiratory symptoms, we report the incidence of pulmonary pathogens using available diagnostic assays during a SARS epidemic. Among patients who had laboratory-confirmed SARS-CoV infection, we also sought to determine the incidence of coinfection with other pulmonary pathogens and whether this was predictive of disease severity.

\section{METHODS}

After the SARS epidemic was identified in Toronto in early 2003, a clinical protocol, drawn up by the NYGH infectious diseases service, was instituted for physicians evaluating patients with fever and respiratory symptoms (pharyngitis, cough, dyspnea and chest discomfort) who may have been exposed to SARS-CoV. This protocol was designed to systematically evaluate all patients for common pulmonary pathogens using available laboratory diagnostics as part of an effort to help exclude a SARS diagnosis and to help focus treatment. The NYGH institutional review board approved the present study.

The clinical protocol included the following for every patient:

- A thorough history, emphasizing epidemiological links, as well as a physical examination and chest imaging (chest $\mathrm{x}$-ray and a computed tomography scan).
- Routine microbiological studies (Gram stain and/or culture) of respiratory specimens, blood and urine. For patients with risk factors, acid-fast bacilli staining and cultures were performed.

- A respiratory infection specimen kit (RISK), designed at NYGH, which included collection supplies and containers for the following assays: SARS-CoV, C pneumoniae, $\mathrm{M}$ pneumoniae and influenza serology; polymerase chain reaction (PCR) for detection of SARS-CoV in blood and respiratory specimens (sputum, throat swabs, nasopharyngeal swabs and bronchoalveolar lavage fluid if available), as well as stool or rectal swabs; viral cultures of nasopharyngeal swab specimens or bronchoalveolar lavage fluid; and urine for Legionella species antigen detection.

- Routine serial hematology and biochemistry.

An off-site, shared hospital laboratory performed the routine microbiological studies. The National Microbiology Laboratory in Winnipeg, Manitoba, performed SARS serology and PCR tests. The sensitivity and specificity of the different SARS diagnostic assays, in addition to other parameters and limitations, are discussed elsewhere (19-21). The C pneumoniae serology (microimmunofluorescence assay), M pneumoniae serology (ELISA), viral cultures, Legionella species urine antigen test and influenza serology (complement fixation) were performed and interpreted by the Central Public Health Laboratory (CPHL) in Toronto (Ontario Ministry of Health and Long-Term Care). Interpretive criteria have been previously published (19) and are discussed in the Results section. Given the unexpectedly high number of blood specimens with serological evidence for acute or recent infection with $\mathrm{C}$ pneumoniae or $\mathrm{M}$ pneumoniae, the respiratory specimens obtained from these patients using the RISK previously described were retrospectively evaluated by nucleic acid diagnostics to confirm the presence of atypical pathogens. Specifically, following collection of the respiratory specimens from patients between March 27 and July 30, 2003, samples were stored at $-70^{\circ} \mathrm{C}$ until thawed once in August or September 2003, during which time they were used to assess for atypical pathogen DNA. PCR for detection of $\mathrm{M}$ pneumoniae in respiratory samples was performed by The Hospital for Sick Children's Diagnostic Virology Laboratory and by the CPHL for $\mathrm{C}$ pneumoniae. Nucleic acid extraction protocols, PCR primers and procedures are available from the authors affiliated with each respective laboratory (SR and MAF).

A total of 117 patients were evaluated at NYGH between March 27 and July 30, 2003. Patient demographic criteria and the results of diagnostic tests ordered were entered in a computer database and updated by two clinical research nurses who communicated laboratory results to NYGH infectious disease consultants. Entered data were verified by supervising authors (GZ and BM) before the final analysis. Patient confidentiality was maintained by labelling each patient with an established reference number. The assigned disease severity category for each patient was based on the most advanced disease state. Table 1 describes the disease severity grading scale. Treatment was at the discretion of the admitting physician in consultation with the infectious diseases service. Antibiotics were administered based on CAP guidelines (22). Those with suspect or probable SARS (based on CDC or World Health Organization criteria) with progressive disease were treated optionally with steroids, ribavirin and/or interferon $(10,11)$. SARS-specific therapy rapidly evolved throughout the course of the present study and preliminary efficacy data have been reported (23). 
TABLE 1

Disease severity scoring system

\begin{tabular}{ll}
\hline Disease severity & Criteria \\
\hline Mild & $\begin{array}{c}\text { Discharged home with follow-up or admitted to } \\
\text { a medical ward } \\
\text { Never admitted to an ICU } \\
\text { Survived }\end{array}$ \\
& $\begin{array}{l}\text { Admission to an ICU for close monitoring and/or } \\
\text { oxygen treatment if not available in a medical ward* }\end{array}$ \\
Moderate & Never intubated \\
& Survived \\
& Required intubation and ventilation \\
Severe & Expired
\end{tabular}

${ }^{*}$ Clinical criteria for transfer to an intensive care unit (ICU) are identical to those published elsewhere $(31,32)$

\section{Statistics}

The incidences of SARS-CoV, other pulmonary pathogens and coinfection were estimated by using simple proportions. Logistic regression models were fit among patients positive for SARS to estimate odds ratios for development of severe disease among patients with and without various coinfections. All $\mathrm{P}$ values from regression models are two-sided and derived from the Wald test. No adjustments were made for multiple comparisons (24).

\section{RESULTS}

Epidemiology and diagnostic study results

Table 2 describes the characteristics of patients evaluated. Over $40 \%$ of the patients were health care workers, and two-thirds were women. The majority of patients were classified as having mild disease. On admission, routine blood, urine and respiratory sample cultures did not yield any pathogenic organisms.

Table 3 summarizes the observed rates of SARS and other pulmonary pathogens. Noteworthy, C pneumonia serology was interpreted as follows by the CPHL: an acute infection was present if one single immunoglobulin (Ig) M titre was greater than 1:10; a recent infection was present if one single $\operatorname{IgG}$ titre was greater than 1:512 or if $\operatorname{IgG}$ was greater than 1:16 and $\operatorname{IgA}$ was at least 1:16. Recent infection implied that the infection occured within the previous three months. A total of 84 patients were tested for C pneumoniae by serology, and $38(45 \%)$ of these were positive for recent infection and two (2\%) were positive for acute infection. Of these 84 patients that had serology completed for $\mathrm{C}$ pneumoniae, 62 also had respiratory specimens available for nucleic acid testing. In addition, there were 19 patients whose respiratory specimens were only tested by PCR for $\mathrm{C}$ pneumoniae (ie, $\mathrm{C}$ pneumoniae serology testing was not performed). One of these 19 patients was found to have a positive result for $\mathrm{C}$ pneumoniae DNA and was also SARSpositive. A total of 103 patients were tested for $\mathrm{C}$ pneumoniae by either PCR or serology, or both; in fact, 62 of 103 patients had both PCR and serology performed. Respiratory samples for nucleic acid testing were available from 31 of 40 patients diagnosed with acute or recent $\mathrm{C}$ pneumoniae by serology, and each was negative by PCR. Ninety-eight patients were tested for M pneumoniae by serology and 13 were positive for acute infection based on a positive IgM. Respiratory specimens from all 13 patients were negative by PCR. A total of 108 patients had M pneumoniae testing: 27 had serology testing only, 10 had PCR only and 71 had both PCR and serology testing.
TABLE 2

\begin{tabular}{|c|c|}
\hline Characteristics & Patients ( $n=117$ ) \\
\hline Median age, years & $\begin{array}{l}47 \text { (minimum, } 17 ; 25 \text { th percentile, } 35 \text {; } \\
\text { 75th percentile, 60; maximum, 96) }\end{array}$ \\
\hline Men, n (\%) & $38(32)$ \\
\hline Health care workers, $n(\%)$ & $51(44)$ \\
\hline \multicolumn{2}{|l|}{ Disease severity, n (\%) } \\
\hline Mild & $90(77)$ \\
\hline Moderate & $5(4)$ \\
\hline Severe & $22(19)$ \\
\hline
\end{tabular}

TABLE 3

Detection of pulmonary pathogens in patients evaluated during a severe acute respiratory syndrome (SARS) epidemic

\begin{tabular}{|c|c|c|}
\hline Diagnostic study & $\begin{array}{c}\text { Number of } \\
\text { patients evaluated }\end{array}$ & $\begin{array}{l}\text { Positive } \\
\text { results, } \mathbf{n}(\%)\end{array}$ \\
\hline SARS test ${ }^{*}$ (PCR or serology) & 117 & $85(73)$ \\
\hline Chlamydophila test serology ${ }^{\dagger}$ & 84 & $40(48)$ \\
\hline Mycoplasma test serology ${ }^{\dagger}$ & 98 & $13(13)$ \\
\hline Legionella urine antigen test & 84 & $0(0)$ \\
\hline Influenza serology ${ }^{\dagger}$ & 83 & $0(0)$ \\
\hline Viral culture & 48 & $3^{\ddagger}(6)$ \\
\hline
\end{tabular}

*Five patients had an autopsy before SARS-associated coronavirus assays were available. Autopsy findings were consistent with SARS; †Only serology results showing acute or recent infection were included; ¥Influenza $A$ was detected in two samples and coxsackie virus was detected in one sample. PCR Polymerase chain reaction

Three patients had positive viral cultures, of which two had influenza A and one had coxsackie virus. Overall, of the 85 patients confirmed to have SARS, 35 (41\%) had laboratory evidence of recent or acute coinfection by serology or PCR (26 with $\mathrm{C}$ pneumoniae and eight with $\mathrm{M}$ pneumonia, as well as one with influenza A by culture). Of the 32 patients with negative SARS testing, 13 were positive for recent infection with $\mathrm{C}$ pneumoniae and five were positive for acute infection with M pneumoniae by serology only.

Impact of pulmonary infection and coinfection on disease severity

Table 4 displays results from logistic regression models that assess the association of SARS and other pathogens with the probability of severe disease. SARS positivity was associated with a statistically significant increased probability of severe disease. Both $\mathrm{C}$ pneumoniae and M pneumoniae positivity by serology were associated with an increased probability of severe disease, but neither association was statistically significant. Other pulmonary pathogens had such low rates of positive results that they were not formally analyzed for their association with severe disease.

Table 5 summarizes the impact of coinfections on the probability of the development of severe disease. To assess the impact of coinfection on the probability of developing severe disease, analyses were restricted to patients who were positive for SARS. Among this group, the odds of severe disease were 


\begin{tabular}{|c|c|c|c|}
\hline & OR & $95 \% \mathrm{Cl}$ & $\mathbf{P}$ \\
\hline \multicolumn{4}{|l|}{ SARS-CoV } \\
\hline Negative, $2 / 32(6 \%)^{\star}$ & 1 & - & - \\
\hline Positive, 20/85 (24\%) & 4.6 & 1.0 to 21.0 & 0.05 \\
\hline \multicolumn{4}{|l|}{ Chlamydophila } \\
\hline Negative serology, 6/44 (14\%) & 1 & - & - \\
\hline Positive serology, $7 / 40$ (18\%) & 1.3 & 0.4 to 4.4 & 0.63 \\
\hline \multicolumn{4}{|l|}{ Mycoplasma } \\
\hline Negative serology, 10/85 (12\%) & 1 & - & - \\
\hline Positive serology, 3/13 (23\%) & 2.3 & 0.5 to 9.6 & 0.27 \\
\hline
\end{tabular}

${ }^{*}$ Fractions and percentages indicate the proportion of patients who had severe disease among patients in the relevant category

compared between patients with and without evidence for coinfection. The only pathogens that yielded positive tests frequently enough to lead to meaningful analyses were $\mathrm{C}$ pneumoniae and $M$ pneumoniae. No statistically significant association was found between increased disease severity in patients with SARS and serological evidence for acute or recent $C$ pneumoniae or M pneumoniae infection.

\section{DISCUSSION}

In the present study, every patient with fever and/or any respiratory tract infection symptoms was assessed for SARS-CoV and other pulmonary pathogens by one or more laboratory assays in an effort to confirm a diagnosis. We were limited because five patients died before any SARS diagnostic assay was available; however, these patients had undergone an autopsy and findings were consistent with a SARS diagnosis (25). In addition, two of these deceased patients had a hospital roommate or spouse who was later confirmed to have a positive SARS assay. Further limiting our study was that, in several instances, not all RISK specimens could be analyzed. This was because the large number of requests for diagnostic tests often overwhelmed clinical and laboratory personnel and resources during the SARS outbreak, requiring prioritization of tests. Specifically, for the 117 patients evaluated, serological tests for $\mathrm{C}$ pneumoniae, $\mathrm{M}$ pneumoniae and influenza were performed on 84 (71\%), 98 (84\%) and 83 (71\%) patients, respectively, while viral culture was performed on $48(41 \%)$ patients and Legionella species urine antigen test on $84(71 \%)$ patients. Nucleic acid detection assays were performed on available respiratory specimens from 62 of 84 patients who had $\mathrm{C}$ pneumoniae serology, while an additional 19 patients were tested by PCR for $\mathrm{C}$ pneumoniae only. For M pneumoniae, 71 of 98 patients tested by serology also had respiratory specimens tested by PCR, while 10 patients only had PCR testing. With these limitations in mind while interpreting the data, the results nevertheless remain informative.

Regarding coinfection in SARS-confirmed patients, routine serology showed a significant incidence of $\mathrm{C}$ pneumoniae and $M$ pneumoniae recent or acute infection, reminiscent of prior CAP studies (13-15). Because serological tests are routine and are considered the most useful means of determining the cause of an outbreak or the prevalence of infection in epidemiological studies (26), one can infer that a significant proportion of patients with SARS have had a recent or an acute
TABLE 5

Logistic regression models for severe disease among patients with laboratory-confirmed severe acute respiratory syndrome-associated coronavirus: Impact of coinfections

\begin{tabular}{lccc}
\hline & OR & $\mathbf{9 5 \%} \mathbf{C l}$ & $\mathbf{P}$ \\
\hline $\begin{array}{l}\text { Chlamydophila } \\
\text { Negative serology, } 5 / 35(14 \%)^{*}\end{array}$ & 1 & - & - \\
Positive serology, $7 / 31(23 \%)$ & 1.8 & 0.5 to 6.2 & 0.39 \\
$\begin{array}{l}\text { Mycoplasma } \\
\text { Negative serology, 10/63 (16\%) }\end{array}$ & 1 & - & - \\
Positive serology, 1/8 (13\%) & 0.8 & 0.1 to 6.8 & 0.80 \\
\hline
\end{tabular}

${ }^{*}$ Fractions and percentages indicate the proportion of patients who had severe disease among patients in the relevant category

infection with $\mathrm{C}$ pneumoniae or $\mathrm{M}$ pneumoniae, and that serological detection of these pulmonary pathogens in someone with fever and respiratory symptoms cannot be used to exclude a diagnosis of SARS. We are cognizant that validated and standardized serological techniques are lacking for atypical bacteria (26), which prompted us to evaluate respiratory specimens for $\mathrm{M}$ pneumoniae and $\mathrm{C}$ pneumoniae by nucleic acid diagnostics from patients diagnosed with such atypical infections by serology. Neither of these pathogens could be detected by PCR in patients confirmed to be infected by serology. We are not the first group to observe such disturbing discordance between PCR and serological diagnostic assays (27). However, one needs to exercise caution with PCR diagnostics in this context, because these also have not been evaluated in a systematic fashion, and especially because the timing of specimen collection and quality of processing will impact results (26). Nevertheless, the negative PCR data for both M pneumoniae and $\mathrm{C}$ pneumoniae in all patients with SARS tested, with the exception of one patient, do suggest a very low likelihood of true coinfection with these atypicals. The gold standard assay for $\mathrm{C}$ pneumoniae and $\mathrm{M}$ pneumoniae is culture, which is, unfortunately, an elaborate and time-consuming procedure requiring specialized media and expertise that was not practical to use during this SARS outbreak (27). It has also not escaped our attention that SARS-CoV may also cause a nonspecific rise in atypical pathogen antibodies; however, to our knowledge, no evidence or literature exists supporting that a positive SARS serology interferes with atypical pathogen serological assays. Currently, our preliminary data do not fully address this possibility.

Although efforts and resources currently concentrate on SARS-CoV and other emerging pathogen diagnostics, the finding of discordant results for better understood and more prevalent atypical pathogens by our group and others, as well as highly variable results among different laboratories $(26,28)$, also emphasizes the desperate need for developing improved gold-standard diagnostic tests for these infectious agents. Diagnosing the next novel respiratory infectious syndrome will also likely require excluding other known pathogens, such as $\mathrm{C}$ pneumoniae, in a timely manner with adequate confidence. This task will only be possible with uniform and standardized interpretation criteria for the different serological and nucleic acid assays. It is uncertain whether SARS will recur on a global level, and the issue of distinguishing between SARS, influenza and other pulmonary pathogens is an issue of intense debate. An executive summary published in 2003 states that "confirming a flu diagnosis means you're relatively safe in ruling 
out SARS" (29). We are unaware of any data that support this statement. Before and during the SARS epidemic in Toronto, there was minimal background influenza (and other respiratory viruses) based on routine surveillance (unpublished data of MAF and FBJ). One patient in our study had culture-positive influenza $A$ and a positive SARS assay. Based on all the data, we currently do not agree with the concept of ruling out SARS by ruling in influenza (or another pathogen) because it has inherent risks that can prove catastrophic. A positive diagnostic result for influenza or another pulmonary pathogen in a patient with progressive respiratory failure may delay recognition of a SARS outbreak, in many ways similar to the experience of the second SARS outbreak in Toronto.

Clearly, the discordance between serology and PCR for $\mathrm{C}$ pneumonia and $\mathrm{M}$ pneumonia limits our ability to accurately assess the true incidence and impact of coinfection by atypical bacteria in those with SARS. For patients with SARS and evidence of $\mathrm{C}$ pneumoniae or $\mathrm{M}$ pneumoniae by serology, recent or acute infection was not associated with increased disease severity. This finding is in contrast to that of a Chinese study in which Chlamydophila-like organisms observed by electron microscopy in deceased SARS patients were thought to contribute to increased disease severity (17).

\section{CONCLUSIONS}

The incidence of coinfection with atypical bacteria in SARSconfirmed patients is dependent on the diagnostic assay used. Serological evidence of recent or acute infection was 30\% for $\mathrm{C}$ pneumoniae and $9 \%$ for $\mathrm{M}$ pneumoniae in patients with
SARS, similar to prior pneumonia coinfection studies (13-15). However, PCR did not detect nucleic acid from either M pneumoniae or $\mathrm{C}$ pneumoniae at the time of respiratory specimen collection in those with positive serology, thus limiting our ability to confidently determine the incidence and impact of atypical coinfection in patients with SARS. When performing diagnostic testing for respiratory pathogens, it is imperative to be aware of the limitations associated with the different tests used. One needs to be very cautious when excluding a SARS diagnosis by ruling in another infectious etiology, because infection with multiple respiratory pathogens has been reported to occur in up to $27 \%$ of patients (30). Based on our experience and data, in a setting where clinical suspicion for SARS is high, specific tests for SARS should be used to confirm or exclude this diagnosis.

ACKNOWLEDGEMENTS: The authors thank the numerous technical staff from the Ministry of Health and Long-Term Care Laboratory Branch and from the National Microbiology Laboratory for their assistance in verifying the accuracy of the laboratory data; all the physicians, nurses, infection control practitioners and numerous other support staff at NYGH to whom we are indebted for their countless hours to help provide the clinical data necessary for this study, while also providing excellent care to all the patients.

GRANT SUPPORT: George Zahariadis is a recipient of a Canadian Institutes of Health Research Fellowship award MFE-102312. 118686. Support was received by grant NIH P30 CA 15704 for statistical analysis.

\section{REFERENCES}

1. Zhong NS, Zheng BJ, Li YM, et al. Epidemiology and cause of severe acute respiratory syndrome (SARS) in Guangdong, People's Republic of China, in February, 2003. Lancet 2003;362:1353-8.

2. Zhao Z, Zhang F, Xu M, et al. Description and clinical treatment of an early outbreak of severe acute respiratory syndrome (SARS) in Guangzhou, PR China. J Med Microbiol 2003;52:715-20.

3. Global surveillance for severe acute respiratory syndrome (SARS). Wkly Epidemiol Rec 2003;78:100-19.

4. Poutanen SM, Low DE, Henry B, et al; National Microbiology Laboratory, Canada; Canadian Severe Acute Respiratory Syndrome Study Team. Identification of severe acute respiratory syndrome in Canada. N Engl J Med 2003;348:1995-2005.

5. Fouchier RA, Kuiken T, Schutten M, et al. Aetiology: Koch's postulates fulfilled for SARS virus. Nature 2003;423:240.

6. Peiris JS, Lai ST, Poon LL, et al; SARS study group. Coronavirus as a possible cause of severe acute respiratory syndrome. Lancet 2003;361:1319-25.

7. Drosten C, Gunther S, Preiser W, et al. Identification of a novel coronavirus in patients with severe acute respiratory syndrome. N Engl J Med 2003;348:1967-76.

8. Ksiazek TG, Erdman D, Goldsmith CS, et al; SARS Working Group. A novel coronavirus associated with severe acute respiratory syndrome. N Engl J Med 2003;343:1953-66.

9. Kuiken T, Fouchier RA, Schutten M, et al. Newly discovered coronavirus as the primary cause of severe acute respiratory syndrome. Lancet 2003;362:263-70.

10. World Health Organization. WHO Guidelines. $<$ http://www.who.int/csr/sars/en/index.html > (Version current at November 21, 2003).

11. Centers for Disease Control and Prevention. Severe acute respiratory syndrome (SARS). <http://www.cdc.gov/ncidod/sars/> (Version current at November 21, 2003).

12. Booth CM, Matukas LM, Tomlinson GA, et al. Clinical features and short-term outcomes of 144 patients with SARS in the greater Toronto area. JAMA 2003;289:2801-9. (Erratum in 2003;290:334).

13. Marrie TJ, Peeling RW, Fine MJ, Singer DE, Coley CM, Kapoor WN. Ambulatory patients with community acquired pneumonia:

The frequency of atypical agents and clinical course. Am J Med 1996;101:508-15.

14. Marston BJ, Plouffe JF, File TM Jr, et al. Incidence of community-acquired pneumonia requiring hospitalization. Results of a population-based active surveillance Study in Ohio. The Community-Based Pneumonia Incidence Study Group. Arch Intern Med 1997;157:1709-18.

15. Lieberman D, Schlaeffer F, Boldur I, et al. Multiple pathogens in adult patients admitted with community-acquired pneumonia: A one-year prospective study of 346 consecutive patients. Thorax 1996;51:179-84.

16. Choi KW, Chau TN, Tsang O, et al; Princess Margaret Hospital SARS Study Group. Outcomes and prognostic factors in 267 patients with severe acute respiratory syndrome in Hong Kong. Ann Intern Med 2003;139:715-23.

17. Hong T, Wang JW, Sun YL, et al. [Chlamydia-like and coronaviruslike agents found in dead cases of atypical pneumonia by electron microscopy]. Zhonghua Yi Xue Za Zhi 2003;83:632-6.

18. Chan PK, Tam JS, Lam CW, et al. Human metapneumovirus detection in patients with severe acute respiratory syndrome. Emerg Infect Dis 2003;9:1058-63.

19. Tang P, Louie M, Richardson SE, et al; Ontario Laboratory Working Group for the Rapid Diagnosis of Emerging Infections. Interpretation of diagnostic laboratory tests for severe acute respiratory syndrome: The Toronto experience. CMAJ 2004;170:47-54.

20. Poon LL, Chan KH, Wong OK, et al. Early diagnosis of SARS coronavirus infection by real time RT-PCR. J Clin Virol 2003;28:233-8.

21. Poon LL, Wong OK, Chan KH, et al. Rapid diagnosis of a coronavirus associated with severe acute respiratory syndrome (SARS). Clin Chem 2003;49:953-5. (Erratum in 2003;49:1234).

22. Mandell LA, Marrie TJ, Grossman RF, Chow AW, Hyland RH. Summary of Canadian guidelines for the initial management of community-acquired pneumonia: An evidence-based update by the Canadian Infectious Disease Society and the Canadian Thoracic Society. Can Respir J 2000;7:371-82. 
23. Loutfy MR, Blatt LM, Siminovitch KA, et al. Interferon alfacon-1 plus corticosteroids in severe acute respiratory syndrome: A preliminary study. JAMA 2003;290:3222-8.

24. Essex-Sorlie D. Medical Biostatistics \& Epidemiology: Examination \& Board Review. Norwalk: Appleton and Lange, 1995.

25. Nicholls JM, Poon LL, Lee KC, et al. Lung pathology of fatal severe acute respiratory syndrome. Lancet 2003;361:1773-8.

26. Dowell SF, Peeling RW, Boman J, et al; C pneumoniae Workshop Participants. Standardizing Chlamydia pneumoniae assays: Recommendations from the Centers for Disease Control and Prevention (USA) and the Laboratory Centre for Disease Control (Canada). Clin Infect Dis 2001;33:492-503.

27. Baum SG. Mycoplasma infection: Immunologic and molecular biologic diagnostic techniques. In: Rose NR, de Macario EC, Folds JD, et al, eds. Manual of Clinical Laboratory Immunology. Washington, DC: ASM Press, 1997:547-57.
28. Maltezou HC, La-Scola B, Astra H, et al. Mycoplasma pneumoniae and Legionella pneumophila in community-acquired lower respiratory tract infections among hospitalized children: Diagnosis by real time PCR. Scand J Infect Dis 2004;36:639-42.

29. SARS vs flu: Can you tell serious disease from common malady? ED Manag 2003;15:97-100.

30. Jennings LC, Anderson TP, Werno AM, Beynon KA,

Murdoch DR. Viral etiology of acute respiratory tract infections in children presenting to hospital: Role of polymerase chain reaction and demonstration of multiple infections. Pediatr Infect Dis J 2004;23:1003-7.

31. Lew TW, Kwek TK, Tai D, et al. Acute respiratory distress syndrome in critically ill patients with severe acute respiratory syndrome. JAMA 2003;290:374-80.

32. Fowler RA, Lapinsky SE, Hallett D, et al. Critically ill patients with severe acute respiratory syndrome. JAMA 2003;290:367-73. 


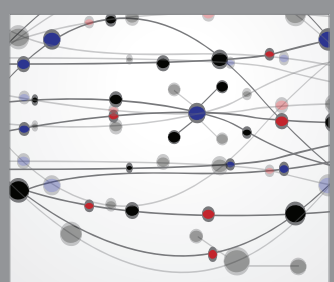

The Scientific World Journal
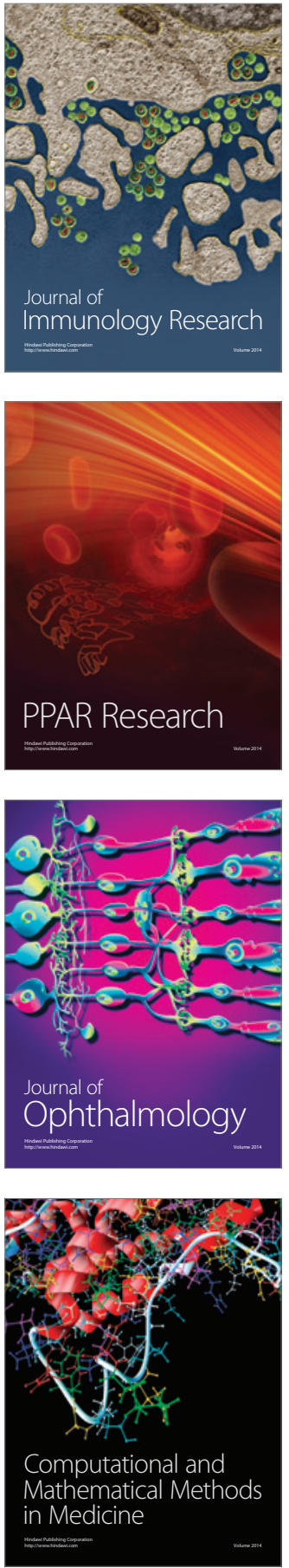

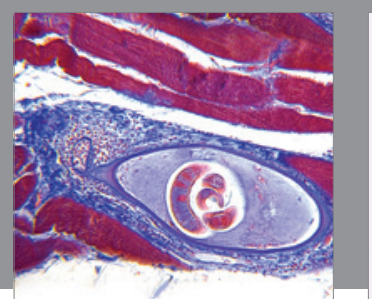

Gastroenterology Research and Practice

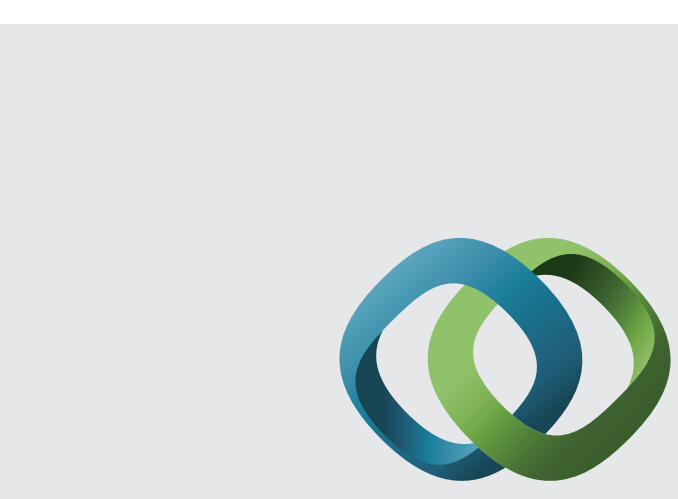

\section{Hindawi}

Submit your manuscripts at

http://www.hindawi.com
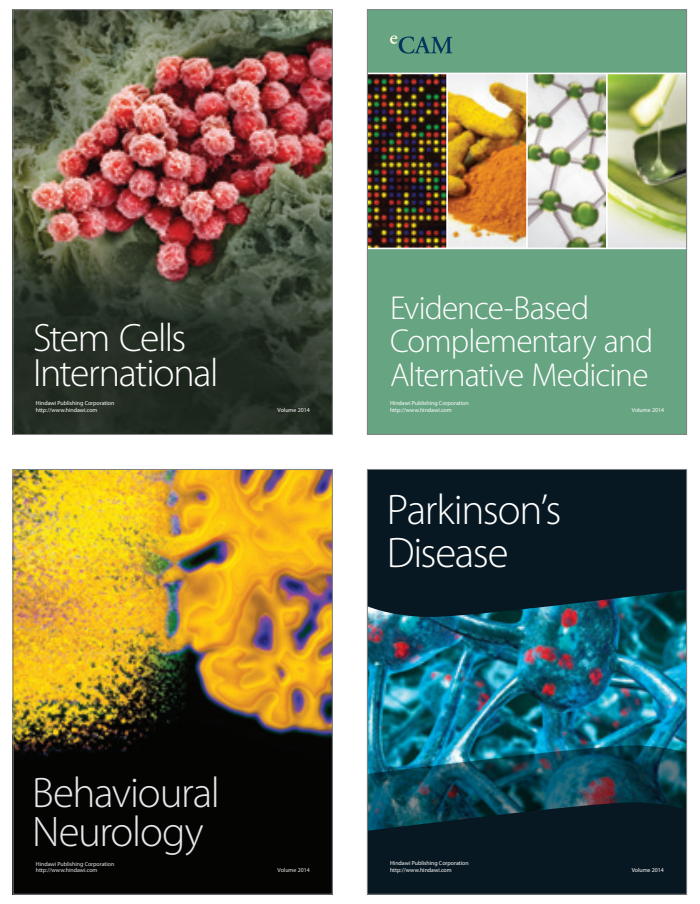
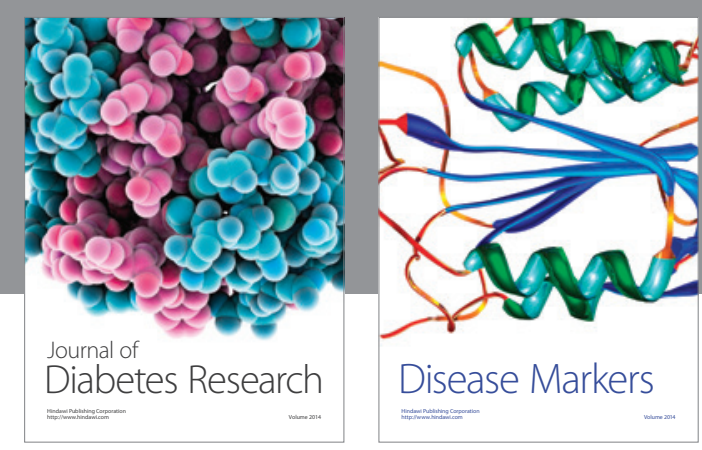

Disease Markers
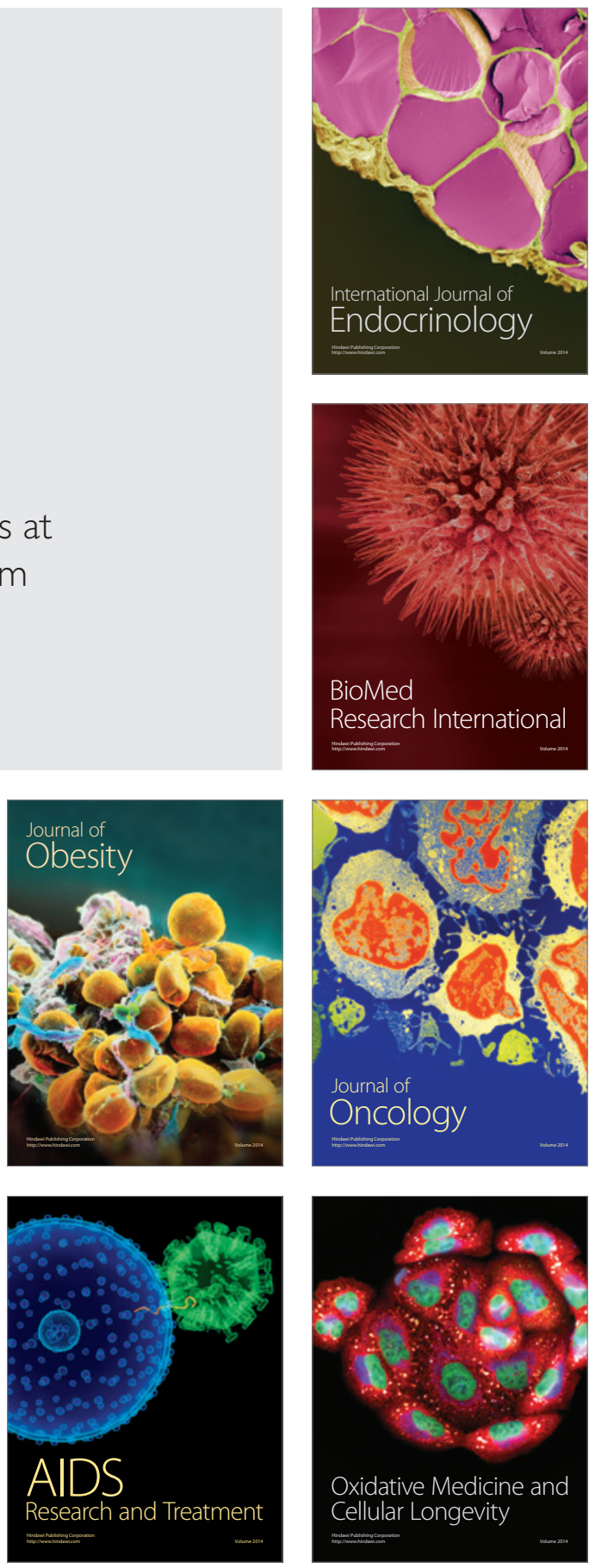